\title{
SUPERSESSION, REPARATIONS, AND RESTITUTION
}

\author{
Caleb Harrison
}

$\rrbracket$ N "SUPERSEDING HISTORIC INJUSTICE", and in subsequent articles, Jeremy Waldron proposes and defends what he calls the Supersession Thesis. ${ }^{1}$ According to the Supersession Thesis, circumstances might be such that the demands of justice in the present can in some sense override the demands of justice arising from cases of historical injustice. ${ }^{2}$ Waldron applies the Supersession Thesis to the appropriation of aboriginal lands by white settlers throughout North America, Australia, and New Zealand, focusing on the history of wrongful appropriation of Maori lands in his home country of New Zealand. He argues that even if it is incontrovertibly true (as he thinks it is) that an injustice occurred when Maori land was wrongfully appropriated, current circumstances are such that the justified claim to reparations possessed by aboriginal groups may be superseded by the claim to a just distribution of resources possessed by the world's existing inhabitants. ${ }^{3}$ While the central claim of the Supersession Thesis - that determinations of justice depend on circumstances - seems to be straightforwardly true, it is less clear what conclusions about reparations are entailed by this fact. Waldron's suggestion that the Supersession Thesis entails that reparations may be superseded seems to conflate claims to restitution (a strong claim) with claims to reparation (a much weaker claim). The Supersession Thesis might entail that claims to restitution can be overridden by changes in circumstance, but I will argue in this paper that the thesis does not entail that claims to reparation are overridden by changes in circumstance; to the contrary, claims to reparation are quite robust to changes in circumstance.

It is worth noting that while this essay focuses on the Supersession Thesis as presented by Waldron, my primary aim is not to respond to Waldron per se. Rather, my primary aim is to examine the conflation of restitutive claims and

1 Waldron, “Superseding Historic Injustice," 26.

2 Exactly in what sense historic injustice can be "overridden" by current circumstances will be explored in detail below, but the general idea should suffice for now.

3 Waldron, “Superseding Historic Injustice," 26. 
reparative claims. Waldron's presentation of the Supersession Thesis is helpful toward this end, both because it jump-started discussions of supersession and because it exemplifies the extent to which the distinction between reparative claims and restitutive claims has not been adequately addressed.

In the first section of this paper, I will examine Waldron's Supersession Thesis in detail, suggesting how we might understand the sense in which claims of historic injustice can be overridden by changes in circumstance. In the second section, I suggest that we can distinguish between restitution and reparation, and that the scope of the former is much more restricted than the scope of the latter. In the third section, I argue that the difference in scope between restitution and reparation can explain why the Supersession Thesis is unlikely to override claims to reparation, though it may help us to understand what restrictions there may be on claims to reparation. I conclude with some remarks on how this discussion might bear on contemporary issues.

\section{SUPERSESSION}

Imagine that three groups of interstellar explorers $-A s, B s$, and $C s-c r a s h$ land on a small planet with a single landmass. ${ }^{4}$ Imagine further that the planet has three bundles of resources-call them $x, y$, and $z$-distributed throughout the landmass, and each resource bundle is sufficient for the flourishing of only one group. Given this initial setup, let us envision a few cases.

Case 1. Suppose that initially (at time $t_{1}$ ), each group stakes a claim to the bundle of resources immediately available to it: $A$ claims $x, B$ claims $y$, and $C$ claims $z$. Given that a bundle of resources is only sufficient for the flourishing of one group, in claiming a bundle of resources each group excludes the other two groups from use of those resources. ${ }^{5}$ The circumstances here are not self-evidently unjust. Each group has sufficient resources for flourishing, and no group is injured by its being excluded from another group's bundle. Given the circumstances at $t_{1}$, it would be unjust for any group to appropriate the resources of another group without that group's consent, and it is compatible with the demands

4 This case is adapted from similar "watering hole" cases presented in Waldron, "Superseding Historic Injustice," and his subsequent articles on supersession, e.g., "Redressing Historic Injustice," and "Settlement, Return, and the Supersession Thesis."

5 In saying that each group excludes other groups from their resources, I intend to be indifferent between their actively excluding individuals from the other groups and their standing ready to exclude others who encroach. I am primarily interested in isolating a case where groups have clear claims on the separate resource bundles, such that the appropriation of another group's resources would clearly be seen as such (and not merely an incidental encroachment). 
of justice that any group exclude any other group from using the resources without consent.

Suppose that at some far later time $\left(t_{2}\right)$, due to an unpredictable and unavoidable natural disaster, group B's resource bundle $y$ disappears. ${ }^{6}$ Without access to their resource bundle, group $B$ will not survive. ${ }^{7}$ Group $C$ 's bundle $z$ is too far away for the $B$ s to reach before dying, but group A's bundle $x$ is within reach. So, the $B$ s encroach on the $A s^{\prime}$ resource bundle, taking enough of it to ensure their own survival. Although $x$ is sufficient to ensure the survival of all the members of $A$ and $B$ combined, it is only sufficient to ensure a subsistence lifestyle-neither group will flourish as they had before. Were group $A$ to exclude group $B$ from their bundle, as they had at $t_{1}$, then group $B$ would not survive. Given the circumstances at $t_{2}$, it would be permissible for group $B$ to appropriate some of group $A$ 's resources without $A$ 's consent; after all, group $B$ 's very survival is at stake, and appropriating resources will not threaten the survival of group $A$. Not only is it just for group $B$ to appropriate some of $A$ 's resources, but it would be an injustice for $A$ to try to exclude $B$ from the resources. What was a just state of affairs in the circumstances of $t_{1}-B$ s being excluded from the resources of As-is now an unjust state of affairs in the circumstances of $t_{2}$.

Case 2. Suppose the initial conditions at $t_{1}$ are the same as in Case 1: there are enough bundles of resources for each group to flourish while claiming exclusive rights to a bundle. Despite the conditions of plenty, suppose that group $B$ wrongfully appropriates some of group $A$ 's resource bundle. Now $A$ is forced to share (at a subsistence level) $x$ with group $B ; B$ shares $x$ with $A$, while maintaining exclusive control over their own resource $y$; and group $C$ maintains exclusive control over their own resource $z$. Given the circumstances here at $t_{1}$-there are resources sufficient for each group, and each group can use their resources

6 We can assume in both cases that the duration between $t_{1}$ and $t_{2}$ is no less than a few generations - or whatever length of time would be necessary to ensure that no individual alive at $t_{2}$ has a direct connection to any individual alive at $t_{1}$.

7 In talking about the "survival" of a group throughout this essay, I am referring to the continued living of the members of the group and not to the continued existence of the group qua group. This distinction is important given the nature of some of the restitutive claims made by groups. For many indigenous groups, for example, certain lands are metaphysically tied to the group identity, such that the group may not be said to survive, despite the survival of individual members of the group, if the individual members of the group are no longer able to bear important relations to the lands in question. There may be a sense in which a member of a group may not be said to survive as herself if she cannot bear certain relations to particular lands. For the purposes of this essay, I will count this as survival, though I do so with the intent of leaving open the question of what justice may demand in a conflict between the survival of a life and the survival of a life of one's own, where this latter concept may include important ties to particular geographies. 
exclusively without injuring another group-B's appropriation of some of $A$ 's resources is an injustice.

Suppose, as with Case 1 , that at some far later time $\left(t_{2}\right)$, an unpredictable and unavoidable natural disaster causes $B$ 's resource $y$ to disappear. Again, $B$ needs resources to survive, and $A$ is the only group within survival range for $B$. Given the circumstances at $t_{2}$, it seems to be permissible for $B$ to appropriate some of $A$ 's resources, regardless of the injustice of $B$ 's appropriation of $A$ 's resources from $t_{1}$ until $t_{2} .{ }^{8}$ Furthermore, it also seems plausible that it would be unjust for the $A$ s to try to exclude the $B$ s from resource $x$. What was an unjust state of affairs in the circumstances of $t_{1}-B s$ appropriating the resources of $A s-$ is now an otherwise just state of affairs in the circumstances of $t_{2}$. Additionally, as an analysis of the permissibility of certain acts and policies, we might arrive at similar conclusions. $B$ 's appropriation of $A$ 's resources was previously impermissible. Now, in $t_{2}$, similar such acts would be permissible.

Case 1 and Case 2 are both cases that are intended to demonstrate how it is that justice is tied to circumstance and how it is that circumstances can affect the ways in which we weigh temporally distant claims in our judgments of justice. In Case 1, we start with a just initial condition, and a change in circumstance changes an (otherwise) identical state of affairs-As excluding $B$ s from a resourcefrom being a just state of affairs to being an unjust one. ${ }^{9}$ Case 2 is more or less the converse of Case 1 and ought to make clearer what is required for supersession to occur. In Case 2, our initial condition is an unjust state of affairs: Bs wrongfully appropriate $A s^{\prime}$ resources. However, a change in circumstances at $t_{2}$ changes an (otherwise) identical state of affairs- $B$ s appropriating $A s^{\prime}$ resources-from being an unjust state of affairs to being a just state of affairs. ${ }^{10}$ Given that the initial condition is unjust, the demands of justice seem to require some form of redress. The exact nature of the required redress, whether it be restitution or reparations (or something else), will likely be determined on a case-by-case basis, but the redress in this case will need to involve at least a transfer of resources from $B$ s to As. However, in the circumstances of $t_{2}, B$ s and $A s$ are both making use of the same bundle of resources, and are doing so at a subsistence level; necessarily, any transfer of resources from $B$ s to $A$ s will threaten the survival of $B s$. It seems

8 At the very least, the skeletal details of the case-including the fact of B's past appropriation-seem insufficiently relevant to defeat $B$ 's claim to access to some of the resources.

9 Alternatively, a change in circumstances changes an (otherwise) identical case-of Bs appropriating As' resources without consent-from being unjust to being just.

10 If end-state talk is suspect here, we can arrive at similar conclusions by analyzing the permissibility of various acts and policies. The changed circumstances between $t_{1}$ and $t_{2}$ affect the permissibility of similar acts: where the $B$ s appropriating the $A$ s' resources at $t_{1}$ is impermissible, the $B$ s appropriating the $A s^{\prime}$ resources at $t_{2}$ is permissible. 
plausible that justice does not demand the sacrifice of the lives of individuals who are themselves innocent of wrongdoing (though they may be the unwitting beneficiaries of past wrongdoings), and so it seems plausible that justice at $t_{2}$ would not demand, and may in fact preclude, that $B$ s transfer resources to $A$ s.

In such cases, Waldron argues that the demands of justice in the present supersede the claims of historic injustice. As should now be clear from the cases above, supersession can be understood to take place when present demands of justice preclude what is required by the demands of justice in remedying historic injustice. Supersession is particularly salient in the context of the aforementioned appropriations of aboriginal lands by white settlers in North America, Australia, and New Zealand. While it might seem that the historic injustices of wrongful appropriations call for redress, Waldron argues that if the supersession argument goes through, it is equally likely that what would be required by the demands of justice in remedying the wrongful appropriation of aboriginal lands is superseded by the present demands of justice in ensuring the survival of innocent beneficiaries of past wrongdoings.

The Supersession Thesis seems quite plausible, and the argument that Waldron makes for it is quite strong. Interestingly, though, Waldron applies his Supersession Thesis to claims of reparations, concluding that it is reparative claims that are superseded by present demands of justice, particularly as in the aforementioned cases of wrongful appropriations of aboriginal lands. He dedicates very little space to discussion of what, exactly, reparations means. It seems, however, that a strong case can be made that supersession is best applied in cases where there exist claims of restitution, rather than reparation-or so I will argue in the penultimate section. First, however, we should examine the difference between claims of restitution and claims of reparation.

\section{REPARATIONS AND RESTITUTION}

The predominant grounds for reparation come from John Locke's views in The Second Treatise of Government. In it, he lays out a theory of reparations that falls out of his views on property and punishment, nicely summarized as follows:

Besides the Crime which consists in violating the Law and varying from the right Rule of Reason, ... there is commonly injury done to some Person or other, and some other Man receives damage by his Transgression, in which Case he who hath received any damage, has besides the right of 
punishment common to him with other Men, a particular Right to seek Reparation from him that has done it. ${ }^{11}$

Three points in this passage are of particular relevance to my purposes in this paper, each of which helps us to distinguish cases where reparative claims are warranted from cases where other forms of redress might be warranted. I will highlight them here, and then address them in turn below. First, reparative claims require injury done to persons. Second, reparative claims require that the injury done to persons results from transgressions - that is, from the wrongful actions of some other person. Finally, reparation calls for redress of some sort, and this redress is owed to the injured and must be settled by the transgressor. ${ }^{12}$

The first point of separation between reparation and other forms of redress is that reparation necessarily involves one party injuring another. Given our set of cases above, we can imagine (contrary to the stipulation of the case) that the $B s^{\prime}$ appropriation of $A s^{\prime}$ resources (in either case) causes no harm to the As; resources are sufficiently abundant that at both $t_{1}$ and $t_{2}$ the $B$ s and the $A$ s are flourishing. In such a case, it may be justified to punish the Bs for the "Crime which consists in violating the Law and varying from the right Rule of Reason," but the $B$ s need not be required to directly redress the $A$ s in any way.

The second point of separation between reparation and other forms of redress is that reparation requires that the injury done to persons be the result of wrongful actions. Returning again to our set of cases above, we can imagine that the Bs' appropriation of $A s^{\prime}$ resources does harm the $A s$, but that the harm is the result of a justified action. This is the case in Case 1 at $t_{2}$, when the $B s^{\prime}$ very survival requires that they appropriate the $A s^{\prime}$ resources, and in Case 2 at $t_{2}$, when the circumstances have changed such that the $B s^{\prime}$ very survival requires that they continue to appropriate the As' resources. ${ }^{13}$ In both cases, the As were made worse off than the Bs as a result of the Bs' actions, but in Case 2, the Bs' actions were in no way wrongful. Likewise, when a jaywalker sprints into traffic and is injured by a vehicle, so long as the driver is abiding by the appropriate traffic laws and norms, we do not think that the driver owes the jaywalker any sort of redress,

Locke, Two Treatises of Government, secs. 10-11.

While these three points are relevant to my argument in this paper, they are not all that can or should be said about reparations. For a more involved discussion, see Boxill, "A Lockean Argument for Black Reparations.”

The second case mentioned here is a bit more complicated in that circumstances alter a state of affairs from including a wrongful action to including a just action. The proper analysis here is to see the state of affairs at $t_{1}$ as one that calls for reparations, while the state of affairs at $t_{2}$ is not. 
because we do not think that the driver's actions were in any sense wrongful, though they were injurious.

The final point of separation between reparation and other forms of redress is that reparation requires that the redress (in whatever form it takes) be owed to those injured by the transgressor. ${ }^{14}$ When the $B$ s wrongfully appropriate the resources of the $A$ s, the $A$ s are owed reparations, and the reparation must come from the Bs. Suppose that at some later time $\left(t_{3}\right)$ after the Bs wrongfully appropriated the resources of the $A \mathrm{~s}$, as they did in Case 1 (at $t_{2}$ ), the $C$ s helped the $A$ s push out the $B s$, and the $C$ s gave the $A$ s enough resources to place them somewhere near the level they would have been had the Bs not made use of the $A s^{\prime}$ resources. In such a case, the As would have been compensated for their loss, certainly, but their claim to reparations would still be valid: the $B$ s would still owe the As something, and no amount of compensation from third parties innocent of the Bs' wrongdoing would change this.

It is worth pausing here to make a few last comments on the preceding points. First, it is important to note that reparations are essentially backward-looking. As we see in Locke's treatise, claims to reparation are generated by injuries resulting from wrongful action that has already occurred. What is required to satisfy a reparative claim will depend on what has transpired between the past wrong and present conditions. This can be contrasted with such forward-looking claims as compensatory claims, which will be discussed below. Forward-looking claims arise from considerations about what might be necessary to attain some future good, rather than from considerations about what might be necessary to restore someone after they have been wronged. ${ }^{15}$ That reparative claims are backward-looking leads us to a second important note regarding the content of reparative claims. Locke notes that the injured party may recover from the transgressor "so much as may make satisfaction for the harm he has suffered." ${ }^{16}$ One thing that might be necessary to make satisfaction for the harm one has suffered is a transfer of material resources sufficient to restore one's own material losses resulting from the wrongful action. It is not the only thing, though. An important feature of the injustice of a wrongful action is the underlying (false) assumption that the injured party has been treated in a befitting manner and that the injured party is not equal to the transgressor in worth or dignity. As such, one

14 Note that reparations might not be in the form of payment. One of the primary purposes of reparations is to restore the harmed, and this restoration might take the form of a social restoration by way of apology, rather than simply a financial restoration by means of a transfer of resources. For more, see Boxill, "Black Reparations." See Boxill, “The Morality of Reparation,” 117-18. 
other thing that might be required to make satisfaction for the harm that one has suffered is a sincere acknowledgment of error on the part of the transgressor. A claim to reparation, if it is to satisfy the injured party for the harm that they have suffered, is likely to include both material and social restoration. ${ }^{17}$

With these points in mind, it seems in the set of cases above that the As have a claim to reparation and that reparation is owed to the $A$ s by the $B$ s: the $B$ s have injured the $A$ s, the injury was the result of a wrongful action, and so the $B$ s must in some fashion redress the $A$ s for the injury the $B$ s caused. Of course, redress can come in a variety of forms, but I will focus on reparation and restitution. One way to understand the difference between reparation and restitution is in terms of their restrictions. The least restrictive form of redress is compensation, which refers broadly to any effort to offset loss. One example of compensation would be a payment by an innocent third party to a party that has suffered a loss (e.g., an insurance company paying homeowners after a flood). Claims of compensation need not necessarily imply blame, or the rightness or wrongness of an action, but merely call for the remediation of the loss of something of value. Reparation is slightly more restrictive and encompasses those forms of redress that involve some kind of transfer from the transgressor to the injured partyfor example, West Germany's payment to Israel after World War II. As noted above, claims of reparation are typically restricted to the injured party and can only be fulfilled by the transgressing party. Restitution is in some sense the most restrictive form of redress. ${ }^{18}$ Restitutive claims can only be held by the party that

17 An anonymous reviewer helpfully pointed out that the distinctions I draw between restitution and reparations suggest a difference in the source of the normative force of each concept. The reviewer noted that on my account, reparation seems to address harms to well-being, while restitution seems to redress violations of legitimate title. I do not have space here to address this insight, other than to note that I did not intend to imply such a difference, nor did I explicitly rely on it in my analysis. But the reviewer helpfully unearthed what had been lurking below the surface in my thoughts - namely, that restitution and reparations can serve different roles in responding to relational breaches. Insofar as a system of title serves to distribute the rights to enjoy certain goods-and to exclude others from them-restitution serves to redress an error in that system and can redress such errors with little to no relationship between members of that system. A car thief need not even engage with me in order to return my stolen car. Well-being, on the other hand, is deeply dependent on relationships, and so redressing harms to well-being will typically require interpersonal engagement. I admit that I am not quite sure what to make of this difference, nor am I sure that I have satisfactorily articulated it, but I thank the reviewer nonetheless for challenging me to think more on this, and I hope to address it in the detail it deserves in further work.

18 Restitution might be considered less restrictive than reparation in that restitutive claims can be held by parties other than the party from whom a valuable was initially taken, and satisfied by parties other than the party that initially took the valuables, whereas reparative claims can only be held by the injured party and satisfied by the transgressing party. 
has a legitimate right to that which was wrongfully taken, and restitutive claims require for their satisfaction the return of the very thing that was taken to the party that has a legitimate right to the taken thing. An example here can help illustrate the requirements of restitutive claims.

Suppose we are in Case 2 (at $\left.t_{1}\right)$ above, where the Bs have wrongfully appropriated the resource of the As; suppose further that this resource is land. Given that the resource in question is land, and land can (for the most part) be returned in full, it seems reasonable to think that the As are owed restitution in the form of a full return of the wrongfully appropriated land. Moreover, in Case 2 (at $\left.t_{1}\right)$, the $B$ s have full and exclusive access to their own resources, the use of which allows the $B$ s to flourish, as well as access to the resources of the $A$ s, the use of which by the $B$ s causes the $A$ s not to flourish. Given that the $B$ s' use of the $A$ s' land causes the $A$ s to fall from a flourishing lifestyle to subsistence living, it seems reasonable to think that in addition to returning the original lands to the $A$ s, the $B$ s owe the As some sort of reparation. Of course, restitution may not always be an option. Suppose we are in a modified version of the above case, where everything is identical except for the nature of the resources: instead of land, the resource is oil. Given that oil is nonrenewable, and so cannot be returned in full, the $B$ s cannot owe the As restitution. ${ }^{19}$ It is still the case, however, that the $B \mathrm{~s}$ are flourishing off their own oil supply while depleting the As' oil supply (and causing the $A$ s to maintain a bare subsistence lifestyle in the meantime), and so it seems reasonable to think that the $B$ s owe the As some sort of reparation.

One final difference between reparations and restitution lies in their responsiveness to changes in the involved parties. To be entitled to reparation, it must be the case that one is injured as a result of the wrongful action of another. For the As (in Case 2, say) to be entitled to reparation at any time after $t_{2}$ it must be the case that the As are harmed by the wrongful appropriation of the Bs. Suppose that by the time $t_{3}$ rolls around all the resource bundles have been depleted to the point of supporting only a subsistence lifestyle-even the previously flourishing $B s$ and the faraway $C s$ are only scraping by. Given that there is no scenario in which the $A s$ at $t_{3}$ are not living a subsistence lifestyle, it cannot be said that the $A$ s from $t_{3}$ and on are entitled to reparation. ${ }^{20}$ To be entitled to restitution, however, it must simply be the case that one is the legitimate rights holder for the value in question and that the value in question can be returned in full. For instance, if we consider the $A$ s in Case 2 (at $t_{3}$ ), then so long as they are

19 Perhaps it could be said that the As still hold a legitimate claim to restitution, but if so, it is a claim that is conditional on the possibility of its being fulfilled.

20 If any of the $A s$ from $t_{1}$ or $t_{2}$ are still around, however, then they would still be entitled to reparation. 
the legitimate rights holders for the wrongfully appropriated land, they are entitled to restitution-regardless of whether they have been injured as a result of the past wrongful appropriation of land by the $B$ s. This would be the case for any other legitimate rights holders too. Perhaps the As were in the process of selling the land to the $C s$ when the $B s$ wrongfully appropriated the land at $t_{1}$. If so, then the $B$ s would owe the land to the $C s$, rather than the As (though they may owe the As reparations as well, to make up for anything the As lost as a result of the delayed sale). ${ }^{21}$ Essentially, the difference is this: reparative claims are restricted to those injured by wrongful action and can be satisfied only by the transgressor, while restitutive claims are restricted to those legitimate rights holders who have been wrongfully separated from something of value and can be satisfied by whoever currently possesses the wrongfully separated valuable.

I am not the first to suggest that the notion of reparations operating in Waldron's work seems different from the notion of reparations at stake in discussions of repairing historic injustices. Over the course of a series of illuminating essays, Rodney Roberts sets out a conception of "rectification" that he argues can help make sense of the lack of interest among white Americans in combating the pernicious effects that historic injustices have had on Black Americans. ${ }^{22}$ While our accounts share some interesting similarities, they have different background assumptions and respond to different lines of inquiry.

In "Why Have the Injustices Perpetrated against Blacks in America Not Been Rectified?" Roberts notes that the notion of "reparation" that Waldron discusses is similar to the "rectification" that he is concerned with. While acknowledging that he is not "attempt[ing] anything like a full account of rectification," Roberts proffers an account that is situated within a framework in which justice has two aspects: distribution (of goods, rights, and duties) and rectification (of unjust distributions). ${ }^{23}$ He identifies three typical features of rectification: (1) restoration, where possible (i.e., the return of that which was unjustly appropriated, or what I refer to as "restitution"); (2) compensation, where necessary (i.e., counterbalancing an unjust loss with something equivalent in value to that loss); and (3) an apology that acknowledges wrongdoing and reaffirms the moral standing of the injured. For Roberts, then, rectification is a component of rectificatory

21 Again, it may be that the restitutive claim is conditional on the possibility of its being fulfilled, but that its fulfillment is currently impossible.

22 For example, see Roberts, "Why Have the Injustices Perpetrated against Blacks in America Not Been Rectified?" "Criminalization and Compensation," and "Another Look at a Moral Statute of Limitations on Injustice." Thank you to the anonymous reviewer who recommended Roberts's work.

23 Roberts, "Why Have the Injustices Perpetrated against Blacks in America Not Been Rectified?" 357 . 
justice, which itself is a response to failures of distributive justice. By situating his conception of rectification within the scope of rectificatory justice, Roberts is able to employ concepts like "rectificatory compensation" to describe the efforts to replace the value of a loss unjustly suffered with something of like value. ${ }^{24}$ He contrasts this with "distributive compensation," which is called for when the distribution of rights and duties obstructs a person's or group's opportunity to participate in the benefits of social cooperation. ${ }^{25}$ With these conceptual tools in hand, Roberts's account seems well suited for identifying the different purposes that may underlie different compensatory policies (e.g., making up for a past injustice contrasted with correcting a maldistribution), which positions him to explain why white Americans have declined to support policies redressing the historic injustices suffered by Black Americans.

While I do not see the arguments that I am offering in this essay to be necessarily in conflict with, or duplicative of, the arguments that Roberts proffers, I do think our alternative accounts serve different purposes and consequently have different features. Where Roberts is concerned with explicating a conception of rectification that can illuminate why Black folks in America have not yet received, and are unlikely to receive, redress, my intent is to show more broadly that changes in circumstances subsequent to historic injustices are primarily-if a problem at all — a problem for what I call restitutive claims. In contrast to Roberts's account of rectification, my notion of restitution is an alternative to, rather than a modifier of, compensation. For example, on my account, universalist efforts to close the racial wealth gap like those proposed by the People's Policy Project are compensatory. ${ }^{26}$ Such policies function by measuring the gap between Black and white wealth and implementing financial policies in such a way that the gap closes over time. These policies need not-and typically do notmake any reference to historic injustices or to replacing a good that was lost with that very good (i.e., Roberts's "restoration" and my "restitution"). Likewise, on my account, particularized efforts to symbolically address historic injustices can be restitutive without being compensatory. For example, the return of a mis-

24 Roberts, "Why Have the Injustices Perpetrated against Blacks in America Not Been Rectified?” $357-58$.

25 Roberts, "Criminalization and Compensation," 143.

26 Author Matt Bruenig notes:

A dividend-paying social wealth fund provides a natural solution to [the problem of wealth inequality by] ... reduc[ing] wealth inequality by moving wealth out of the hands of the rich who currently own it and into a collective fund that everyone in the country owns an equal part of. It then reduces income inequality by redirecting capital income away from the affluent and parceling it out as a universal basic dividend that goes out to everyone in society. (Social Wealth Fund for America, 52-53) 
appropriated artifact of historic or religious significance-by the museum that held it to the nation from which the artifact originated-may restore the good that was taken without serving to address any sort of imbalance the artifact's absence has caused since its initial misappropriation. Such actions would be restitutive without being compensatory. By distinguishing between various forms of redress, my account positions me to explain why changes in circumstances have different impacts on these various forms of redress. ${ }^{27}$ Given these distinctions, we can reexamine Waldron's Supersession Thesis to see whether he is right to conclude that reparative claims can be superseded by circumstance.

\section{CAN REPARATIVE CLAIMS BE SUPERSEDED?}

The Supersession Thesis argues that the demands of justice in the present may preclude the satisfaction of reparative claims involving past harms resulting from wrongful action. Given the previously drawn distinction between reparative and restitutive claims, it seems warranted to think that the Supersession Thesis might be best applied to restitutive claims rather than reparative claims. To see why, let us return to our cases. Suppose we are in Case 2. The Bs wrongfully appropriated the resources of the $A s$ at $t_{1}$, and (at least prior to $t_{2}$ ) the $A s$ seem entitled to redress as a result of the wrongful appropriation. This redress might take any number of forms, but it seems reasonable to expect that it would be in accord with the demands of justice that the $B$ s return the land in full (as restitution) and that they transfer resources to the $A$ s to redress them for whatever harms have befallen the As as a result of the wrongful appropriation (as reparation). Suppose, however, that before either restitution or reparation is paid, circumstances change such that we find ourselves at $t_{2}$ (the disaster has struck and the $B \mathrm{~s}$ need some of $A s^{\prime}$ resources to survive). Circumstances at $t_{2}$ preclude restitution; restitution requires that the originally appropriated resource be returned in full to the legitimate rights holder, but there is no way to return the land to the As without threatening the very survival of the $B$ s in the process. The Supersession Thesis seems to hold with respect to restitution. ${ }^{28}$

27 A further difference between our accounts is that the account I offer in this essay does not depend on a particular conception of justice (e.g., as divided between distribution and the rectification of maldistributions). My account should be compatible with theoretical frameworks that are concerned with, for instance, restorative justice, transformative justice, or transitional justice. See, e.g., Murphy, The Conceptual Foundations of Transitional Justice; Daly, “Transformative Justice”; and Walker, Moral Repair. torial rights, and the relation of each to land. I have elided those distinctions here for the sake of simplicity, but they do call for brief comment. If we think of the relevant resources 
It is not clear, however, that the circumstances at $t_{2}$ preclude reparation. Entitlement to claims of reparation requires that a person be injured as a result of a transgressor's wrongful action and that the transgressor owe the injured party some form of redress intended to restore the injured, either materially or socially (or both). There is no reason, given the details of Case 2 at $t_{2}$, to think that the circumstances are such that all possible forms of financial or social restoration are incompatible with the present demands of justice. The only circumstances in which this would hold would be the circumstances in which any sort of transfer of resources whatever would threaten the survival of the Bs. Short of such dire circumstances, there are any number of ways that the Bs might redress the As: priority positions in the government could be reserved for $A \mathrm{~s}$, special assistance programs could be instated to ensure that all As have access to the limited resources available, or a fund could be set up for the $A$ s to which the $B$ s would be responsible for contributing. In short, there is a lot that might be done to move toward full reparation - at the very least, there seems to be space for reparative action sufficient to push back against Waldron's claim that circumstances in Case 2 at $t_{2}$ are such that reparative claims are superseded by changes in circumstance.

One might object that Case 2 at $t_{2}$ is precisely a case wherein the circumstantial difference is so dire that reparations are precluded. After all, the disaster moved both groups to hand-to-mouth living - surely there is no room in such a lifestyle for any transfer of resources from $B$ s to $A$ s. Even if we grant that the circumstances of Case 2 at $t_{2}$ preclude a transfer of resources, reparative claims, as noted before, need not only concern a claim to the transfer of resources from

in the case as being tied to particular lands and we think of those lands in terms of property rights, where thinking of lands in terms of property rights centers our thought on claims to exclusive use or possession (e.g., Waldron, "Superseding Historic Injustice," 20), then supersession will be a live concern. If the satisfaction of a restitutive claim to land (conceived of in terms of property rights) requires that the land be transferred, for exclusive use and ownership, from, for example, the $B$ s to the $A$ s, then it may be the case that demands of justice would preclude such a transfer due to the threat it would pose to the survival of the Bs.

If we think of the relevant resources in the case as being tied to particular lands but we think of those lands in terms of territorial rights, where thinking of lands in terms of territorial rights centers our thought on claims to territorial sovereignty-or the exclusive right to make, adjudicate, and enforce laws within a region without interference from outside forces-then supersession is less likely to be a live concern. If the satisfaction of a restitutive claim to land (conceived of as territorial rights) requires that the right to territorial sovereignty be transferred from, for example, the $B$ s to the $A$ s, then it is unlikely that demands of justice will preclude such a transfer because such a transfer would pose no threat to the survival of the $B$ s. For more on the distinction between property rights and territorial rights, and their relevance to potential cases of supersession, see Nine, "Superseding Historic Injustice and Territorial Rights" and "Ecological Refugees, States Borders, and the Lockean Proviso." 
the transgressor to the injured party. Reparative claims can also concern such socially restorative actions as sincere public apologies, and such actions are not precluded, even at the limit represented by Case 2 at $t_{2}$. Reparative claims are robust to changes in circumstance, and if they are not superseded here at the limit, it is hard to imagine in which circumstances they are superseded. ${ }^{29}$

Returning to Waldron's actual discussion, it is important to recall why Waldron was concerned, first and foremost, with making sense of how changes in circumstance affect the reparative claims generated by historic injustice. Waldron was particularly interested in the wrongful appropriation of aboriginal lands by white Europeans in the seventeenth to nineteenth centuries. In New Zealand in particular, several generations have passed since the wrongful appropriation of Maori lands by white settlers, and Waldron now wonders whether circumstances have changed in such a way as to preclude reparative claims by aboriginal peoples. He correctly notes that while returning land to the Maori immediately after its appropriation would have been relatively benign in effect, giving "exclusive rights [today] would mean many people going hungry who might otherwise be fed and many people living in poverty who might otherwise have an opportunity to make a decent life." ${ }^{30}$ It is certainly reasonable to conclude that the injustice that would result from kicking thousands of people off of the land that they require to live an adequate life would outweigh the justice that could be satisfied by returning wrongfully appropriated land to the descendants of the injured. Still, this injustice seems only to preclude restitution, yet Waldron claims that "it has priority over reparation" (27). Drawing tighter the parallel between the cases examined above and Waldron's real-world example of wrongfully appropriated Maori lands, it seems that precluding restitution leaves wide open the possibility of satisfying reparative claims. Priority positions in the

29 One interesting line of thought that I do not have the space to explore here has to do with the nature of the reparations that would satisfy some reparative claim. Presumably, when we speak of "reparations" we speak of some set of policies that, together with their effects, will satisfy the injured party's reparative claim. Suppose the set of policies includes the following: (1) a sincere public apology, (2) structural reform, and (3) a transfer of resources. All three are necessary to satisfy this particular reparative claim, and the set of the three is sufficient to do so. Note that there is nothing requiring this set of policies to be implemented at once. Even in Case 2 at $t_{2}$, we can imagine 1 and 2 being implemented, with 3 set for implementation once circumstances allow for it. In fact, the implementation of 1 and 2 , before 3 becomes possible, might increase the likelihood that 3 actually comes about when it becomes feasible. See, e.g., the dialogue between Rodney Roberts, Laurence Thomas, and Bernard Boxill in the following essays: Roberts, "Why Have the Injustices Perpetrated against Blacks in America Not Been Rectified?" and "Toward a Moral Psychology of Rectification”; Thomas, "Morality, Consistency, and the Self”; and Boxill, "Power and Persuasion." Waldron, "Superseding Historic Injustice," 26, hereafter cited parenthetically. 
government could be reserved for people of Maori descent, or special assistance programs could be instated (and funded by taxes on those without Maori ancestry, or implemented as tax credits to those of Maori descent) to ensure that all Maoris have access to resources sufficient for financial or social restoration. If it is land specifically that is of concern, rather than just the harms that resulted from having land wrongfully appropriated from the Maori people, reparations might entail a program wherein Maori groups receive government assistance in purchasing any property within their initial land holdings that comes up for sale in the future. The details are not without difficulty, of course, but I hope that I have made my point clear: the Supersession Thesis may preclude restitution in the case of wrongfully appropriated Maori lands, but it seems to have little to say about reparations.

Given that there is a clear distinction between restitutive claims and reparative claims, we might wonder whether Waldron really did run the two together. The main evidence supporting the conclusion that he did can be found in his original 1992 article on the Supersession Thesis. He begins the article by explicitly stating, "The topic of this article is reparation," before explaining that his understanding of reparation is one that recognizes that reparation has symbolic importance in addition to monetary implication (6). He goes on to note that he is considering arguments for "full and not merely symbolic reparation-a demand not just for remembrance but for substantial transfers of land, wealth, and resources in an effort to actually rectify past wrongs" (7). After referring almost exclusively to reparation throughout his article, he concludes by noting that the main claim of the Supersession Thesis only "has priority over reparation which might carry us in a direction contrary to that which is indicated by a proscriptive theory of justice" (27). Only once does the idea of restitution arise, and then in reference to the confiscation of property that has a questionable transactional history. Waldron notes that we often organize our lives and expectations around our possessions in a meaningful way and that "upsetting these expectations in the name of restitutive justice is bound to be costly and disruptive" (16, emphasis added). This statement is intended to support his conclusion that changes in circumstance-in this case, changes in a particular possession's role in the lives of potential owners - can supersede what might be demanded by reparative justice. That he uses restitutive justice as an example of a reparative claim that can be superseded seems to strongly support the contention that he runs the two together.

Supposing I am right, one might reasonably concede that Waldron's proposal was ultimately just that restitution — not reparations - can in some circumstances be superseded by changes in circumstance and wonder whether my essay 
has any further contribution to make to the discussion. While I would be content with merely this concession, I do think my argument implicates a broader concern with assumptions underlying the Supersession Thesis. By limiting the scope of his argument to "full and not merely symbolic reparation," or efforts "to actually rectify past wrongs," Waldron attempts to ward off bad-faith actions that purport to address past wrongs: false apologies, insultingly low payoffs, or other conduct that actors can proffer as reparative acts that supposedly justify moving on from the historic injustices. Of course, such conduct should be written off as being in bad faith. But without explicitly distinguishing between reparations and restitution, as I do in this essay, I worry that the Supersession Thesis is liable to fall prey to a scenario whereby any effort to redress past wrongs that falls short of restitution would be dismissed as a bad-faith effort, and any effort that survives the bad-faith dismissal would trigger supersession.

For instance, suppose that "full and not merely symbolic reparation" required a formal apology by the state, a truly massive transfer of land and wealth, and the creation of new local and national public entities responsible for the promotion of the rights and well-being of the historically injured group. Suppose further that these could not be promoted simultaneously: no transfer of land or wealth at the appropriate scale could take place without a nationwide acknowledgment that the historic injury needed to be redressed, and no such acknowledgment could take place without a radical change in social attitudes toward the historically injured group, and no such attitudinal change could take place without a long-term education and consciousness-raising campaign at local and national levels. The Supersession Thesis suggests that only the entire bundle counts as "full and not merely symbolic reparation," and so a change in circumstances affecting any constituent part of the bundle may trigger supersession, undermining the implementation of the whole bundle of policies. If a change in circumstances were to make a massive land transfer inconsistent with the demands of justice right now, then the demands of justice now would supersede any claim to land transfer, even if those claims could be warranted after implementing policies that altered present landowners' attitudes toward such a transfer.

On my account, we can explain why land transfer now is superseded by present claims to land, while holding open the possibility that such a transfer could be a component of a broader, diachronic policy bundle. Namely, present circumstances supersede the restitutive claims to land, and so presently preclude such a land transfer. But present circumstances do not supersede reparative claims, and so a reparative package that includes the possibility of future land transfer is still a viable response to historic injustice. True, we will not know whether the reparative policy bundle that includes a transfer of land will satisfy the demands of the 
present reparative claims at the moment of implementation, because it is only once the land transfer fails to transpire that we can know for sure that the call to delay land transfer was made in bad faith. But the fact that we cannot know at the moment of implementation whether a land transfer-a necessary component of a sufficient reparative policy bundle-is being delayed in bad faith does not mean that any sufficient transfer of land is necessarily superseded by the demands of justice in the present, nor does it mean that any conduct short of the transfer of land is a bad-faith act merely purporting to be reparative. Even if Waldron's Supersession Thesis is, ultimately, just a thesis about the effect of present circumstances on restitutive claims, it is still worthwhile to adopt the distinction between restitution and reparations that I offer in this essay so as to understand just how much room for reparations remains available in circumstances where restitution seems to be off the table.

\section{CONCLUDING REMARKS}

The Supersession Thesis has wide-ranging applicability. Waldron focuses his discussion on historic, wrongful land appropriation, but the general claim of the Supersession Thesis can be applied to any case where circumstances have changed so dramatically over time that we would be wise to pause and consider how those changing circumstances affect the shape that justice might take. One case that takes this form is the case of Black reparations in the United States. The arguments made for Black reparations come in a variety of forms, though some of the most prominent in the philosophical literature today are the counterfactu$\mathrm{al}$ and the inheritance arguments. ${ }^{31}$ The cases for Black reparations that depend on demonstrating ongoing injury to Blacks in the present are less relevant to the Supersession Thesis. ${ }^{32}$ After all, the circumstances that injure Black Americans are the very circumstances in which we find ourselves; there is no sense to be made of circumstances superseding themselves. The cases for Black reparations that depend on demonstrating that Black Americans today are entitled to claim redress for harms done to their ancestors, however, seem to be highly relevant to the Supersession Thesis. ${ }^{33}$

31 See Boxill, "Black Reparations," for more detail.

32 Here I refer to arguments for reparations on the basis of ongoing injuries caused by Jim Crow policies, racist redlining policies backed by both local and federal governments, and racist carceral practices, among others. Ta-Nehisi Coates's 2014 article "The Case for Reparations" in the Atlantic is a prominent example of such an argument for reparations on the basis of ongoing injury.

33 Andrew Cohen and Janna Thompson each give different arguments for how we might understand the entitlement to reparative claims held by present-day Black Americans as being 
If we apply the Supersession Thesis as understood by Waldron, then it seems right to conclude that circumstances have changed such that reparative claims are superseded by the demands of justice in the present. Confiscating the land formerly belonging to slaveholders and distributing it to emancipated slaves ought to have been done post-emancipation, and it is plausible to think that present-day descendants of slaves have inherited the right to that land. Confiscating the land today, and distributing the land to the descendants of slaves, however, is almost certainly precluded by the demands of justice in the present. Millions of (otherwise) innocent beneficiaries of the historic injustice of slavery would be forced from the very land that is necessary for their well-being, and it seems implausible that such an action would be compatible with justice given the circumstances of the present. As understood by Waldron, the Supersession Thesis would preclude reparations of this form. Once we distinguish between reparations and restitution, however, we can see that the Supersession Thesis at most says that it is the restitutive claim to land that is precluded by the demands of justice in the present. Assuming that there exists a plausible argument legitimately linking present-day conditions of Black Americans to entitlements to reparations held by their slave ancestors, then it seems that any form of reparation short of restitutive land redistribution would not satisfy the conditions required by supersession and would therefore be compatible with the demands of justice in the present day. ${ }^{34}$

The Supersession Thesis is an important reminder that justice depends on the circumstance, and different circumstances will lead to different results when weighing competing claims of justice. Given the relevance of circumstance to the determinations of justice then, it is of the utmost importance that we make crystal clear the nature of the competing claims involved. We must recognize the distinction between restitutive claims and reparative claims, and Waldron's version of the Supersession Thesis does not make this distinction. Once the dis-

grounded in the legitimate entitlement to reparative claims held by their ancestors. Cohen's argument relies on claims about parental duties, while Thompson's argument relies on claims about inheritance rights. See Cohen, "Compensation for Historic Injustices"; and Thompson, "Historical Injustice and Reparation."

The assumption that such an argument exists is one that Waldron himself attacks-he thinks that counterfactual arguments for reparations fall short, and he offers up a version of property rights that he thinks cuts the inheritance argument off at the knees ("Superseding Historic Injustice," sec. 2, esp. pp. 14-18). However, given that reparative claims are distinct from restitutive claims and that reparative claims need not be linked to any specific property, even if his version of property rights is correct, it would still only support the supersession of restitutive claims. 
tinction is made, however, it seems clear that though the Supersession Thesis might have the final say regarding restitution, it is silent regarding reparations. ${ }^{35}$

calebharrison@icloud.com

\section{REFERENCES}

Boxill, Bernard. "Black Reparations." Stanford Encyclopedia of Philosophy (Spring 2016). https://plato.stanford.edu/archives/sum2016/entries/black -reparations.

_- "A Lockean Argument for Black Reparations." Journal of Ethics 7, no. 1 (March 2003): 63-91.

"The Morality of Reparation." Social Theory and Practice 2, no. 1 (Spring 1972): 113-23.

. "Power and Persuasion." Journal of Social Philosophy 32 , no. 3 (Fall 2001): $382-85$.

Bruenig, Matt. Social Wealth Fund for America. The People's Policy Project, 2018. https://www.peoplespolicyproject.org/wp-content/uploads/2018/o7/ SocialWealthFund.pdf.

Coates, Ta-Nehisi. "The Case for Reparations." Atlantic, June 2014. https://www. theatlantic.com/magazine/archive/2014/06/the-case-for-reparations/ $361631 /$.

Cohen, Andrew I. "Compensation for Historic Injustices: Completing the Boxill and Sher Argument." Philosophy and Public Affairs 37, no. 1 (Winter 2009): 81-102.

Daly, Erin. "Transformative Justice: Charting a Path to Reconciliation." International Legal Perspectives 12, nos. 1-2 (2002): 74-183.

Locke, John. Two Treatises of Government. Edited by Ian Shapiro. New Haven: Yale University Press, 2003.

Murphy, Colleen. The Conceptual Foundations of Transitional Justice. Cambridge: Cambridge University Press, 2017.

Nine, Cara. "Ecological Refugees, States Borders, and the Lockean Proviso." Journal of Applied Philosophy 27, no. 4 (November 2010): 359-75.

35 For helping me to sharpen the arguments on offer in this essay, I would like to thank Andrew Cohen, Cara Nine, Helen Frowe, and my life-giving cohort. For inspiring this essay and introducing me to the issues of reparations in the first place, I would like to thank Bernie Boxill. 
_- "Superseding Historic Injustice and Territorial Rights." Critical Review of International Social and Political Philosophy 11, no. 1 (2008): 79-87.

Roberts, Rodney C. "Another Look at a Moral Statute of Limitations on Injustice." Journal of Ethics 11, no. 2 (June 2007): 177-92.

- "Criminalization and Compensation." Legal Theory 11, no. 2 (June 2005): 143-62.

- "Toward a Moral Psychology of Rectification: A Reply to Thomas and Boxill." Journal of Social Philosophy 33, no. 2 (Summer 2002): 339-43.

- "Why Have the Injustices Perpetrated against Blacks in America Not Been Rectified?" Journal of Social Philosophy 32, no. 3 (Fall 2001): 357-73.

Thomas, Laurence. "Morality, Consistency, and the Self: A Lesson from Rectification." Journal of Social Philosophy 32, no. 3 (Fall 2001): 374-81.

Thompson, Janna. "Historical Injustice and Reparation: Justifying Claims of Descendants." Ethics 112, no. 1 (October 2001): 114-35.

Waldron, Jeremy. "Redressing Historic Injustice." In "Liberal Democracy and Tribal Peoples: Group Rights in Aotearoa/New Zealand." Special issue, University of Toronto Law Journal 52, no. 1 (Winter 2002): 135-60.

- "Settlement, Return, and the Supersession Thesis." Theoretical Inquiries in Law 5, no. 2 (2004): 237-68.

-. "Superseding Historic Injustice." Ethics 103, no. 2 (October 1992): 4-28. Walker, Margaret Urban. Moral Repair: Reconstructing Moral Relations after Wrongdoing. Cambridge: Cambridge University Press, 2006. 